\title{
Comparative Study of Sustainable Development Planning in Southeast Asia Countries
}

\author{
Atih Rohaeti Dariah ${ }^{1 *}$, Muhammad Syukri Salleh², Shereeza Binte Mohamed Saniff ${ }^{3}$, Ernawati $^{4}$ \\ ${ }^{1}$ Faculty of Economic and Business, Universitas Islam Bandung, Bandung 40116, Indonesia \\ ${ }^{2}$ Centre for Islamic Development Management Studies (ISDEV), Universiti Sains Malaysia, Pulau Pinang 11800, Malaysia \\ ${ }^{3}$ Faculty of Islamic Development Management, Universiti Islam Sultan Sharif Ali (UNISSA), BE 1721, Negara Brunei \\ Darussalam \\ ${ }^{4}$ Faculty of Engineering, Universitas Islam Bandung, Bandung 40116, Indonesia
}

Corresponding Author Email: atih@unisba.ac.id

https://doi.org/10.18280/ijsdp.150407

Received: 6 August 2018

Accepted: 12 January 2020

\section{Keywords:}

sustainable development planning, SDGs, national longterm and midterm development plan

\begin{abstract}
The Sustainable Development Goals (SDGs) have become applicable since January 2016 and is expected to be fully implemented in 2030. This article examines how Indonesia, Malaysia, and Negara Brunei Darussalam (NBD) as three Muslim countries in Southeast Asia with different economic, social, and political conditions commit to respond to the SDGs. The study used content analysis method to analyze the long and medium-term development plan documents in three stages. The researchers interviewed the planners to get an overview of the process of achieving the SDGs. The results of this study showed that the three countries have their own specific institutional agencies that undertook similar steps in achieving the goals, i.e. aligning the existing plan documents with SDGs, examining the indicator and data availability for monitoring and evaluation, establishing communication, and building the capacity with all stakeholders. The three countries have already internalized the SDGs in their planning development. However, when it comes to SDGS targets and indicators, Malaysia and NBD have a lower score than Indonesia because as a country with a lower level of development, Indonesia has more desired outcomes with quantitatively explicit and specific indicators.
\end{abstract}

\section{INTRODUCTION}

Every country has its own way to implement the 2030 agenda for 'Sustainable Development Goals (SDGs)'. The approach of one country to achieve the SDGs actually depends on number of populations, environment, political and socialcultural conditions [1].

Indonesia, Negara Brunei Darussalam (NBD), and Malaysia are countries with Muslims majority in Southeast Asia that have four issues to be addressed. Firstly, a question of whether or not Islamic values are inherent in their development planning. Secondly, the difference in number and quality of population. Indonesia is a big-sized country with 257.6 million population but only has a mean years of schooling (MYS) of 7.9 years. Malaysia is inhabited by 30.3 million population and has a better quality of MYS of 10.1 years. NBD, a very small country with a population of 'only' 0.4 million has MYS of 9 years [2]. Thirdly, the monarchy form of government versus republic. Indonesia is a republic state covering 34 provinces and 514 districts/municipalities, while Malaysia and NBD are monarchy countries. Malaysia follows a democratic system form of government and NBD holds on its Malay Islamic Monarchy ("MIB") philosophy. Fourthly, middle-income countries versus high-income countries. Indonesia is low middle income country, meanwhile Malaysia has ranked up from middle to upper income country; and NBD is a high income country [3]. Condition and interaction among the four components above will specify the methods, measures, process, and substance in achieving the 17 goals, 169 targets and 241 indicators of SDGs [4].

To help reach 169 targets, United Nation's Sustainable Development Solutions Network (SDSN) has provided a three chapters guide of Getting Started with the Sustainable Development Goals - a Guide for Stakeholders. Achieving such complex goals of SDGs' requires thorough plans with the government taking the lead and also support from business, academia, and civil society in the form of active engagement [5]. This article aims to examine how the three Muslim countries with their significant economic, social, and political differences adopt the SDGs into their respective development plans.

\section{SUSTAINABLE DEVELOPMENT PLANNING}

Sustainable development has definitions and principles that integrates economic, social, and environment dimensions. However, many countries have experienced practical difficulties in integrating the three dimensions and putting the concept into operation [6]. Some scholars such as Roberts et al. [7], Moles et al. [8], Taylor and Hamnett in William [9], Nolon and Salkin [10] advocate the role of planning to achieve sustainable development.

The grounded in theories of linear rationality, is a classical planning paradigm that sees planning as 'an organized, conscious and continual attempt to select the best available 
alternatives to achieve specific goals [11]. Sustainable development planning is an aspect of strategic management that countries have significant experience with and are quite good at [12].

Furthermore, Williams [9] proposes strategic planning as the most appropriate place to integrate Ecologically Sustainable Development (ESD) into the planning system. More importantly, Roughley [13] proposes framework of sustainable development planning as the basis value for ecologically sustainable planning with its eco-centric philosophy and social justice principles. These values incorporate certain characteristics including participation, inclusiveness, discourse, knowledge, skills, values and strategies from multiple disciplinary perspectives, interdependence, intrinsic value, and diversity. The characteristics have been placed in one dimension of the framework that integrates head, heart, and land as interrelated parts of a cornerstone to build organisational and management structures that facilitate ecologically sustainable planning.

Meanwhile, AlQahtany et al. [14] showed that the framework of sustainable development has four key dimensions, namely environmental, social, economic, and planning dimensions. Communication technology dimension (ICT) is an implicit dimension which will be included in all of the four key dimensions.

In the context of SDGs, it seems there has to be a more conical planning to achieve the goals. SDSN (Sustainable Development Solutions Network) proposes backcasting, a problem-solving framework that envisions how the development should progress with intermediate actions based on long-term quantitative targets. Backcasting is not forecasting that estimates the probabilities of various outcomes based on expected trends. Backcasting begins with a projection of the desired outcome(s) and works backwards to understand what is needed for the realization [5]. This framework is relevant since the focus of study is projection of the desired outcome(s) shown by quantitative and qualitative indicators as it has been written in medium term planning documents of three countries mentioned earlier.

\section{METHODOLOGY}

There are two types of data in this study, namely primary data from planners who run SDGs in their respective countries; and secondary data from the long-term and medium-term development plan documents of Indonesia, Malaysia, and NBD. The study of development plan documents applies content analysis in three stages. The document being analyzed is the long-term and medium-term development plan in progress with the duration of time presented in Table 1.

The Indonesian RPJPN 2005-2025 has a period of 20 years consisting of four phases of the National Medium-term Development Plan, namely phase I in 2005-2009, phase II in 2010-2014, phase III in 2015-2019 and phase IV in 2020-2024 [15]. At the time of research, the ongoing RPJMN is phase III RPJMN for 2015-2019. While in Malaysia is the 2010-2020 Long-Term Development Plan with a shorter term, which is 10 years. The medium-term development plan document currently underway is the EMP 2016-2020. NBD has a longterm development plan of up to 28 years that breaking down into five-year medium term planning phases. Plan Year 20172022 has not been published yet, so that the medium term plan document being used is the previous one of year 2012-2017. The time difference in the long-term and medium-term development plans of these three countries depends on the development needs of each country. That difference is not an issue in comparing the development in three countries. The most important thing is to find out what efforts each country has done in responding to the SDGs that have been included in their development plan document.

Table 1. A long-term and medium-term development plan document of Indonesia, Malaysia, and NBD

\begin{tabular}{cccccccc}
\hline \multirow{2}{*}{ No } & \multirow{2}{*}{ Development Plan } & \multicolumn{6}{c}{ Country } \\
\cline { 3 - 7 } & & Indonesia $^{1)}($ year $)$ & \multicolumn{2}{c}{ Malaysia $^{2)}($ year $)$} & \multicolumn{2}{c}{ Brunei $^{3)}($ year $)$} \\
\hline 1 & Long-Term & $2005-2025$ & 20 & $2010-2020$ & 10 & $2007-2035$ & 28 \\
\hline 2 & Medium-Term & $2015-2019$ & 5 & $2016-2020$ & 5 & $2012-2017$ & 5 \\
\hline
\end{tabular}

Source:

1) National Long-term Development Plan 2005-2025, National Medium-term Development Plan 2015-2019

2) Malaysia Long-Term Development Plan: New Economic Model (2010-2020), Eleventh Malaysia Plan (2016-2020): Anchoring Growth on People

3) Brunei Darussalam Long-Term Development Plan (2007-2035), Eleventh National Development Plan RKN10 (2012-2017)

In the first stage, scope of long-term development plan elements was identified. We identify vision statements, mission, goals, targets, strategies, and policies direction. The identification results will show the number of statements. Stage two is giving a score to the whole statement. The researcher adopted from Beke and Conroy who have developed a method to evaluate the extent to which a plan's policies promote sustainable development principles [16]. Each policy is evaluated as suggested in the plan $($ score $=1$ ) or required by the plan $($ score $=2)$. Policies that are "suggested" contained key words such as encourage, consider, intend, or should. Policies are "required" if they contained words such as shall, will, require, or must. Yet we added the number 0 for the formulation of the policy of no awareness to sustainable development principles, so that we coded each policy depending on whether it is required (score=2), or suggested (score $=1$ ) or nothing $($ score $=0$ ) in the plans. The third stage is computing the score in two steps, i.e. to sum all scores and then divide them by the maximum possible score and multiply them by 100 to standardize the indices.

Content analysis for the medium-term development plan document is narrowing down straight to target and indicator identification. The identification results will show the number of targets and indicators that are aligned with the SDGs. Stage two is giving a score to each indicator. Researchers coded each indicator according to whether it is (clearly) quantitative data (score $=2)$ or just general information as qualitative data (score $=1)$. Meanwhile, stage three has the same process carried out for content analysis of long-term development plan documents.

NBD's National Eleventh Development Plan Year 20122017 documents are not explicitly displayed targets and indicators. There are only formulations of six strategic development thrusts. The researcher then elaborates the 
existing sentence formulations. When there are 'will' word such as will implement, will conduct, will improve, will continue, will strength, will foster, will make certain, will upgrade, those 'will' words get score of 2; and the absence of those words get the score of 1 .

Meanwhile, getting the information from key informants who run the SDGs is done through in-depth personal interviews directly withy planners in the planning agencies of each country. The list of questions of in-depth personal interviews is as follows:

(1) To what extent is the Government/Kingdom's commitment to the global SDGs agenda?

(2) Is Indonesia/Malaysia/NBD actively involved in international meetings preparing for the SDGs?

(3) What are the steps taken by the Government of Indonesia/Malaysia/ NBD in responding to SDGs?

(4) Is the SDGs agenda incorporated in the development planning?

(5) If the SDGs agenda has already incorporated in the development planning, in what form would it be?

(6) Besides creating the program, does it also produce program achievement indicators?

(7) What is the process or mechanism of preparing operational plans for the implementation of SDGs in Indonesia/Malaysia/NBD?

(8) Who are the parties involved in the preparation of operational plans for the implementation of SDGs in Indonesia/Malaysia/NBD?

(9) How far is the implementation of a participatory approach in preparing operational plans for implementing SDGs in Indonesia/Malaysia/NBD?

(10) What is the mechanism of monitoring and evaluation of the implementation of SDGs?

(11) Are there special regulations prepared to broadly disseminate the SDGs so that they become a reference for all development stakeholders?

(12) Is there a special agency formed in charge of planning and implementing activities to achieve the SDGs? If there is, is it attached to or under certain ministries?

(13) Are there many SDGs centers in educational institutions, local governments, and NGOs in Indonesia/Malaysia/NBD?

(14) To what extent such activities support the achievement of SDGs in Indonesia/Malaysia/NBD?

\section{RESULT AND DISCUSSION}

This section displays the result of study on steps of SDGs implementation in three countries. Based on the result of the interview with planners in three countries, there are similar steps are forming institutional framework for SDG and mapping SDGs with development plan document. Institutional framework is the organizational structure implementing the SDGs that equipped with tasks and functions. Mapping SDGs with development plan documents includes efforts to put SDGs side by side with the vision, mission, goals, and strategies of development contained in the long-term development plan document.

Whereas, the medium-term plan documents for the case of Indonesia and Malaysia is pairing directly with national targets and indicators aligned with the SDGs, which means it includes data readiness and gap analysis.

\subsection{Institutional framework}

These three countries have a specific institution for the implementation of SDGs. In Indonesia, the President of Indonesia directly leads SDGs implementation, as stated in the Presidential Decree Number 59 Year 2017 on Implementation and Achievement of Sustainable Development Goals. The Presidential Decree is also a legal basis of institutional arrangement to implement SDGs with involvement of all stakeholders through the establishment of National Coordination Team. The structure of National Coordination Team consists of Steering Committee, Implementing Team, Working Groups, Experts Team and SDGs Secretariat. Members of Implementing Team and Working Groups are representatives of government, philanthropy and business society, civil society organizations, academics and experts to ensure inclusiveness and none of the principles are left behind. This inclusive set up is to develop national ownership and is implemented at national and subnational levels. The SDGs Secretariat is under the Ministry of National Development Planning/Bappenas [17].

In Malaysia, SDG planning and implementation are taken care of by two key institutions under the Malaysian Prime Minister's Office, namely the Economic Planning Unit (EPU) and the Implementation and Coordination Unit (ICU). While EPU develops SDG's planning documents for implementation, ICU coordinates and advices the EPU in the context of evaluation as well as monitors the impact of SDG's indicators. In general, EPU functions as a planning institution that is responsible in advising the government on economic matters, drawing up detailed development plans, economic analysis, the review and evaluation of project, and programing and coordinating technical assistance. The ICU, on the other hand, ensures the coordination and implementation of those government policies, programs, and project at the national, intergovernmental, and federal and state levels. EPU and ICU are supported by ministries, state governments, government departments as well as non-government organizations (NGOs), Civil Society Organizations (CSO), and private sectors players. One department which collaborates closely with EPU and ICU and plays a key role in collecting, coordinating, keeping, and updating data and info on SDG is Malaysian Department of Statistics (DoS).

More specifically, SDG in Malaysia is managed by a National SDG Council chaired by the Prime Minister himself. Below the National SDG Council is a Steering Committee chaired by Director General of the EPU. The Steering Committee, inter alia, oversees 5 Working Committees, namely Working Committees on Inclusivity, on Well-Being, on Human Capital, on Environment and Natural Resources, and on Economic Growth. Each Working Committee takes charge of specific goals of UNDP's SDGs.

In Negara Brunei Darussalam (NBD), a special committee was formed in October, 2016 for the purpose of implementing and monitoring SDGs in NBD. The special committee known as "Special Committee for National Coordination of the Sustainable Development Goals (SDGs)" or ("The SDG Committee") is formed under the Department of Economic Planning and Development (JPKE) headed by Acting Director General of JPKE who is also the Deputy Permanent Secretary, Economics and Finance, Prime Minister's Department of NBD. Responsibilities of the SDG committee such as categorizing the indicators, identifying ownership of the indicators, and monitoring the status of the indicators. The 
SDG Committee's role is to monitor and provide update on the status of the indicator. The SDG Committee collates all information and updates. However, it is up to the various ministries or government agencies to provide the details and update to the SDGs Committee. Although there is no force of law to report, most ministries or government agencies do keep the SDG Committee in the loop by sending documents or details of meet related to SDGs.

\subsection{Mapping SDG with the plan document}

The long term development plan of the three countries were drafted long before global commitment of SDGs were agreed. Each country has formulated its vision, mission, goals, targets and strategy of development in accordance with their conditions and strategic issues faced. The spirit of sustainable development consisting the three dimensions is already provided in their plan documents and only differ in the use of language planning with the explicit use in the statements of shall, will, require, encourage, or simply must consider, intend, and should.

The result of content analysis of long-term development plan document is presented in Table 2 below.

Malaysia has a higher score because the formulation of language planning is very clear, firm, and focus such as green growth' will be a way of life, enhancing inclusiveness towards an equitable society, inclusivity ensures all Malaysians benefit, improving wellbeing for all, healthy individuals and happy households, living in cohesive and united communities, ensuring sustainability of growth, et). Whereas, Indonesia is lower since there are many formulas using complicated language and a widely broad scope comprising eight missions, eight goals and 13 directions of development without having any strategic formulation. NBD's Long Term Development Plan consists of three goals with eight strategies. In turn, the eight strategies are guided by the 50 policy directions to develop the strategies.

Table 2. Scoring for long term development plan Indonesia, Malaysia and NBD

\begin{tabular}{cccc}
\hline VMGTSPd* & Indonesia & Malaysia & NBD \\
\hline Number of Statement & 147 & 25 & 69 \\
Score 2 & 38 & 9 & 15 \\
Score 1 & 107 & 16 & 52 \\
Score 0 & 2 & & 1
\end{tabular}

*Vision, Mision, Goals, Targets, Strategies and Policies Direction

Table 3. Total score of sustainable development plan for long term development in Indonesia, Malaysia and NBD

\begin{tabular}{ccc}
\hline No & Long-Term Development Plan Document & Score \\
\hline 1 & $\begin{array}{c}\text { Indonesia National Long-Term Development Plan } \\
\text { Year 2005-2025 }\end{array}$ & 61.90 \\
& $\begin{array}{c}\text { Malaysia Long-Term Development Plan: New } \\
\text { Economic Model 2010-2020 }\end{array}$ & 68 \\
& $\begin{array}{c}\text { Brunei Darussalam/NBD Long-Term } \\
\text { Development Plan 2007-2035 }\end{array}$ & 59.42 \\
\hline
\end{tabular}

Table 4. National targets and indicators of SDGs achievement in Indonesia, Malaysia, and NBD

\begin{tabular}{|c|c|c|c|c|c|c|c|c|}
\hline \multirow{2}{*}{ No } & \multirow{2}{*}{$\frac{\text { T and I* }}{\text { Goals }}$} & \multicolumn{2}{|c|}{ Global } & \multicolumn{2}{|c|}{ Idn } & \multicolumn{2}{|c|}{ Malay } & \multirow{2}{*}{$\begin{array}{c}\text { NBD } \\
\text { Policy }\end{array}$} \\
\hline & & $\mathrm{T}$ & $\mathrm{I}$ & $\mathrm{T}$ & I & $\mathrm{T}$ & I & \\
\hline 1 & End poverty in all its forms everywhere & 7 & 12 & 4 & 21 & 5 & 17 & 4 \\
\hline 2 & $\begin{array}{l}\text { End hunger, achieve food security and improved nutrition and promote sustainable } \\
\text { agriculture }\end{array}$ & 8 & 14 & 3 & 8 & 6 & 18 & 2 \\
\hline 3 & Ensure healthy lives and promote well-being for all at all ages & 13 & 26 & 8 & 24 & 7 & 19 & 4 \\
\hline 4 & $\begin{array}{l}\text { Ensure inclusive and equitable quality education and promote lifelong learning } \\
\text { opportunities for all }\end{array}$ & 10 & 11 & 5 & 16 & 1 & 1 & 7 \\
\hline 5 & Achieve gender equality and empower all women and girls & 9 & 14 & 5 & 11 & 2 & 5 & 2 \\
\hline 6 & Ensure availability and sustainable management of water and sanitation for all & 8 & 11 & 6 & 22 & 4 & 4 & 5 \\
\hline 7 & Ensure access to affordable, reliable, sustainable and modern energy for all & 5 & 6 & 3 & 5 & 4 & 4 & 3 \\
\hline 8 & $\begin{array}{l}\text { Promote sustained, inclusive and sustainable economic growth, full and productive } \\
\text { employment and decent work for all. }\end{array}$ & 12 & 17 & 9 & 11 & 6 & 11 & 3 \\
\hline 9 & $\begin{array}{l}\text { Build resilient infrastructure, promote inclusive and sustainable industrialization } \\
\text { and foster innovation }\end{array}$ & 8 & 12 & 3 & 8 & 2 & 3 & 2 \\
\hline 10 & Reduce inequality within and among countries & 10 & 11 & 4 & 10 & 5 & 5 & \\
\hline 11 & Make cities and human settlements inclusive, safe, resilient and sustainable & 10 & 15 & 7 & 16 & 1 & 1 & 5 \\
\hline 12 & Ensure sustainable consumption and production patterns & 11 & 13 & 5 & 5 & 1 & 1 & 6 \\
\hline 13 & Take urgent action to combat climate change and its impacts & 5 & 7 & 2 & 2 & 3 & 3 & 1 \\
\hline 14 & $\begin{array}{l}\text { Conserve and sustainably use the oceans, seas and marine resources for } \\
\text { sustainable development. }\end{array}$ & 10 & 10 & 4 & 4 & 3 & 5 & \\
\hline 15 & $\begin{array}{l}\text { Protect, restore and promote sustainable use of terrestrial ecosystems, sustainably } \\
\text { manage forests, combat desertification, and halt and reverse land degradation and } \\
\text { halt biodiversity loss }\end{array}$ & 12 & 14 & 7 & 8 & 5 & 7 & 1 \\
\hline 16 & $\begin{array}{l}\text { Promote peaceful and inclusive societies for sustainable development, provide } \\
\text { access to justice for all and build effective, accountable, and inclusive institutions } \\
\text { at all levels }\end{array}$ & 12 & 23 & 8 & 21 & 3 & 3 & 2 \\
\hline 17 & $\begin{array}{l}\text { Strengthen the means of implementation and revitalize the Global Partnership for } \\
\text { Sustainable Development }\end{array}$ & 19 & 25 & 11 & 16 & 3 & 3 & 2 \\
\hline & Total & 169 & 241 & 94 & 208 & 63 & 117 & \\
\hline
\end{tabular}

Source: Report of the Inter-Agency and Expert Group on Sustainable Development Goal Indicators (E/CN.3/2016/2/Rev.1)

RPJMN of Indonesia in 2015-2019, Eleventh Malaysia Plan (2016-2020), Eleventh National Development Plan in NBD (2012-2017)

*Targets (T) and Indicators (I) 
NBD score 59.42 that economic content is relatively dominant than social and environment. Wawasan Brunei 2035 mentioned about a sustainable economic growth. The three main goals mentioned in Wawasan Brunei 2035 preceded SDGs. Wawasan Brunei 2035 was created after consultation with the people of NBD. A lot of hard work went into it by the Department of Planning, JPKE. About ten years ago, in 2007, JPKE had to conduct numerous roadshows to all the stakeholders of NBD to formulate Wawasan Brunei 2035.

The calculation in stage 3 which have been explained in the research method is used to get the total score and the results are presented in Table 3.

Furthermore, the three countries align their development plan with SDGs. The alignment process is not limited to identifying the suitability of purpose and target, but also the indicators. The result of content analysis is presented in Table 4.

Globally, there are 169 targets and 241 indicators of SDGs. However, since nine indicators are repeated under two or three different targets, the actual total number of individual indicators in the list is 230 [18]. All indicators have taken into account different national realities, capacities, and levels of development so that they are applicable to all. Thus, each country will adopt global targets and indicators in accordance with its national circumstances.

Indonesia has already had national indicators similiar to global indicators, proxy indicators, and additional indicators that enrich global indicators. There are a total number of 208 indicators in RPJMN that are in line with SDGs. Since RPMJN was composed in 2014, there must be some new SDGs indicators that have not yet listed in it. Indonesia added those indicators in National Plan of SDGs Action for 2017-2019 with the total indicators of 320 . Of the total number of SDGs indicators, Indonesia has developed the metadata to ensure uniformity and comparability along with necessary disaggregation. One target that is considered not relevant for Indonesia is the proportion of seized, found, or surrendered arms whose illicit origin or context has been traced or established by a competent authority in line with international instruments.

Malaysia has a different case. The results of study on data readiness and gap analysis show there are 5 indicator categories: available, partially available, partially available and need further development, not available, and not applicable. The available category has the most number of 91 indicators, while the partially available and need further development has 72 indicators. The not applicable category is the indicator that goes against Islamic principles such as LGBT. Meanwhile, the process of indicators screening is still ongoing in NBD. Similar to Malaysia, NBD also rejects indicator that is not in accordance with Islamic principles.

Of the 169 targets and 241 indicators, the world's biggest attention focused on goal number 3 (ensure healthy lives and promote well-being for all at all ages), goal number 16 (promote peaceful and inclusive societies), and goal number 17 (strengthen the means of implementation and revitalize the global partnership). In fact, 26 percent of the total target and 30.7 percent of the total SDG indicators are charged to these three goals. Goal number 3 becomes the focus of SDGs, namely people and their well-being as the purpose of development with 13 targets and 26 indicators. Goal number 16 and goal number 17 show the conditioning and means to ensure the achievement of the SDGs. Goal number16 which emphasizes the legal and governance dimensions has 12 targets and 23 indicators including security, justice, human rights enforcement, and the application of good governance principles. Whereas, goal number 17 with 19 targets and 25 indicators aims at providing the means of implementation, namely financial capacity, technology, capacity-building, trade, systemic issues, multi-stakeholder partnerships, data, monitoring, and accountability. This finding suggests that efforts to achieve SDGs require supports in the form of human capital, financial capital, and social capital under a system of good governance.

Of the 94 targets and 208 indicators, it turns out that Indonesia has the same pattern as the global one. Through comparing global targets and indicators with the national midterm development plan (RPJMN), the results show that goal number 3, 16, and 17 dominate the targets and indicators of Indonesia's SDGs. Most indicators are in goal number 3 with the total number of 24.

Likewise, in Malaysia 'EMP' development plan document, the most indicators are in goal number 3 with 17 indicators, but the numbers are lower than those in Indonesia. This illustrates that Indonesia needs to achieve more of the desired outcome (s) in health and welfare development given the wider scope of health problems and coverage area in Indonesia compared to Malaysia. While for NBD, there are 4 formulations of policies relevant to goal number 3 . It means there are only a few targets to achieve. NBD is a small country with a population of only 0.156 percent of Indonesia's population but has a per capita income of 7.35 times higher, which means the goal of healthy lives and well-being for all at all ages in NBD is surely more guaranteed.

Malaysia's next focus would be goal number 2 and goal number 1 . Goal number 2 has 6 targets and 19 indicators, exceeding global and Indonesian indicators because it breaks down the type of commodity of sustainable food productions systems. Meanwhile, goal number 1 has 17 indicators, surpassing global indicators since it targets to eradicate poverty with a few pockets describing various low income groups. But, the number of these indicators is lower than those in Indonesia.

For the NBD, as it is explained earlier, Brunei Darussalam's National Eleventh Development Plan Year 2012-2017 document did not display targets and indicators explicitly. There was only formulation of the six strategic development thrusts we called policy. By aligning the SDGs with six strategic development thrusts, we found there are 49 policies related to SDGs. They are mostly in goal number 4 (Ensure inclusive and equitable education and promoting lifelong learning opportunities for all) as an expression of the RKN10 theme, namely knowledge and innovation, increase productivity, accelerate economic growth.

Moreover, to determine the explicitness of indicator and policy, a score is given for each indicator in the Indonesia and Malaysia plan documents, and for each policy in the NBD plan document. The result of score is shown in Table 5.

Based on the results of the scoring, the majority of indicators of each goal get a score of 2 because it is explicitly quantitative and specific. Indicators that do not have the explicitness as those of score 2 indicators, get a score of 1 . After adding up the total scores, the sums then divided by the maximum possible score, that is the number of indicators times score 2 and multiplied by 100 . The result of calculation are as follows: the score for Indonesia's 2014-2019 RPJMN is 89.90, Malaysia's EMP 2016- 2020 is 79.91, and the RKN 10 of NBD in 2012-2017 is 78.57. Holding the highest score, 
Indonesia has successfully aligned the 2015-2019 RPJMN with SDGs by appearing a comprehensive sustainable development indicator close to SDGs with explicit/firm content in quantitative indicators and specific. Meanwhile, the indicators listed in EMP-11 and RKN 10 documents are still limited compared to the SDGs. Malaysia is now prioritizing the SDGs according to 11 Malaysia Plan for 2016-2020 and focus on goal number $1,2,3,5,9,14,15,17$. The low value of NBD is caused by the plan documents being analyzed (the RKN10 of 2012-2017), a plan that had already been executed and was not adapted to the targets and indicators of SDGs.

Indonesia affirms SDGs implementation plan in the national action plans (RAN) for the implementation of 2017-2019 period, where the number of indicators exceed global indicators. Indonesia is also preparing the roadmap for achieving the SDGs up to 2030 that will become a reference for composing the 2020-2024 and 2025-2029 RPJMN. RAN is elaborated in detail into four pillars of sustainable development, i.e. pillar of economic development, pillar of law and management, pillar of environment, and social pillar. Each pillar presents three matrices, where matrix part I contains SDGs target indicator, part II contains programmes and government activities, part III contains program and non governmental organizations' activities. Matrix part I uncovers the SDGs relevant to each pillar, target, indicators' codes and names, data source, description, measurement, baseline (2015), target achievement for 2016-2019 period, and implementing agencies. Matrix part II and III reveal the program/activity/activities indicators, baseline (2015), measurement, annual targets for 2016-2019 period, the 5 years budget allocation indicative (IDR in million), funding sources, and implementing agencies. Thus, Indonesia has already had detailed and comprehensive plans to achieve the SDGs. Inclusive process can be seen from matrix part III where the business world and civic social organizations become an integral part of the efforts to reach SDGs in Indonesia. The active civic and asocial organizations currently involved are big islamic organizations such as National Zakat Amil Agency (BAZNAS) that has funding sources from religious obligatory, infaq, and sadaqah. BAZNAS has a commitment with UNDP to mainstream the religious philanthropic activities to SDGs. Currently, there are 111 NGO organizations that have already contributed voluntarily to pass on what they do.

Table 5. Scoring indicators for mid term development plan Indonesia, Malaysia and NBD

\begin{tabular}{|c|c|c|c|c|c|c|c|c|c|c|}
\hline \multirow[t]{3}{*}{ No } & \multirow[t]{3}{*}{ Sustainable Development Goals } & \multirow[t]{3}{*}{$I^{*}$} & \multirow{2}{*}{\multicolumn{2}{|c|}{$\begin{array}{c}\underset{\text { RPJMN }}{\text { 2015-2019 }} \\
\text { Score }\end{array}$}} & \multirow[t]{3}{*}{$\mathbf{I}^{*}$} & \multirow{2}{*}{\multicolumn{2}{|c|}{$\begin{array}{l}\text { EMP } \\
\text { 2016- } \\
\text { 2020 } \\
\text { Score }\end{array}$}} & \multirow[t]{3}{*}{$\mathbf{P}^{*}$} & \multirow{2}{*}{\multicolumn{2}{|c|}{$\begin{array}{c}\text { NDP/RKN } \\
\text { 2012-2017 } \\
\text { Score }\end{array}$}} \\
\hline & & & & & & & & & & \\
\hline & & & 2 & 1 & & 2 & 1 & & 2 & 1 \\
\hline 1 & End poverty in all its forms everywhere & 21 & 42 & & 17 & 24 & 5 & 4 & 2 & 3 \\
\hline 2 & $\begin{array}{c}\text { End hunger, achieve food security and improved nutrition } \\
\text { and promote sustainable agriculture }\end{array}$ & 8 & 14 & 1 & 18 & 4 & 16 & 2 & & 2 \\
\hline 3 & Ensure healthy lives and promote well-being for all at all ages & 24 & 46 & 1 & 19 & 18 & 10 & 4 & 6 & 1 \\
\hline 4 & $\begin{array}{c}\text { Ensure inclusive and equitable quality education and promote } \\
\text { lifelong learning opportunities for all }\end{array}$ & 16 & 32 & & 1 & 2 & & 7 & 10 & 2 \\
\hline 5 & Achieve gender equality and empower all women and girls & 11 & 20 & 1 & 5 & 2 & 4 & 2 & & 2 \\
\hline 6 & $\begin{array}{c}\text { Ensure availability and sustainable management of water and } \\
\text { sanitation for all }\end{array}$ & 22 & 18 & 6 & 4 & 8 & & 5 & 8 & 1 \\
\hline 7 & $\begin{array}{c}\text { Ensure access to affordable, reliable, sustainable and modern } \\
\text { energy for all }\end{array}$ & 5 & 10 & & 4 & 4 & 2 & 3 & 6 & \\
\hline 8 & $\begin{array}{l}\text { Promote sustained, inclusive and sustainable economic } \\
\text { growth, full and productive employment and decent work for } \\
\text { all. }\end{array}$ & 11 & 12 & 5 & 11 & 22 & & 3 & 2 & 2 \\
\hline 9 & $\begin{array}{l}\text { Build resilient infrastructure, promote inclusive and } \\
\text { sustainable industrialization and foster innovation }\end{array}$ & 8 & 18 & & 8 & 8 & 3 & 2 & 2 & 1 \\
\hline 10 & Reduce inequality within and among countries & 10 & 16 & 2 & 3 & 4 & 1 & & & \\
\hline 11 & $\begin{array}{l}\text { Make cities and human settlements inclusive, safe, resilient } \\
\text { and sustainable }\end{array}$ & 16 & 22 & 5 & 5 & 8 & 1 & 5 & 4 & 3 \\
\hline 12 & Ensure sustainable consumption and production patterns & 5 & 6 & 2 & 1 & 2 & & 6 & 10 & 1 \\
\hline 13 & Take urgent action to combat climate change and its impacts & 2 & & 2 & 3 & 4 & 1 & 1 & & 1 \\
\hline 14 & $\begin{array}{l}\text { Conserve and sustainably use the oceans, seas and marine } \\
\text { resources for sustainable development. }\end{array}$ & 4 & 8 & & 5 & 6 & 2 & & & \\
\hline 15 & $\begin{array}{c}\text { Protect, restore and promote sustainable use of terrestrial } \\
\text { ecosystems, sustainably manage forests, } \\
\text { combat desertification, and halt and reverse land degradation } \\
\text { and halt biodiversity loss }\end{array}$ & 8 & 22 & 2 & 7 & 14 & & 1 & 2 & \\
\hline 16 & $\begin{array}{l}\text { Promote peaceful and inclusive societies for sustainable } \\
\text { development, provide access to justice for all and build } \\
\text { effective, accountable and inclusive institutions at all levels }\end{array}$ & 21 & 34 & 4 & 3 & 6 & & 2 & 2 & 1 \\
\hline \multirow[t]{2}{*}{17} & $\begin{array}{l}\text { Strengthen the means of implementation and revitalize the } \\
\text { global partnership for Sustainable Development }\end{array}$ & 16 & 14 & 9 & 3 & 4 & 1 & 2 & 2 & 1 \\
\hline & Total & 208 & 334 & 40 & 117 & 140 & 46 & 49 & 56 & 21 \\
\hline
\end{tabular}

Planning quality can be a groundwork for the success of implementation, but there is no permanent guarantee for it. SDGs 2018 report state that transitioning towards more sustainable and resilient societies requires an integrated approach that recognizes challenges such as changing climate, conflict, inequality, persistent pockets of poverty and hunger, 
rapid urbanization and environmental degradation. The solution for those challenges is also interrelated. Beside that, transitioning to sustainable and resilient societies hinges on responsible management of finite natural resources [19]. It means it would necessarily take a paradigm shift to answer all questions.

\section{CONCLUSION}

This study showed that the development plans of Indonesia, Malaysia, and NBD have already accommodated the dimensions of sustainable development with only a difference in the emphasis. Among the three countries, Indonesia takes a lead, is very responsive, and more structured in managing the SDGs. High commitment is marked by the issuance of Presidential Decree that generate National and Sub National Action Plan of 2017-2019 and Roadmap of 2017-2030.

There is alignment between the level of development and the size of the country with SDG targets and indicators. Having a large population but categorized as a low-income country in 2018, Indonesia has a high spirit to increase the level of its development and managed to have the most SDGs targets and indicators compared to Malaysia and NBD. For Indonesia, getting the highest score for SDGs achievement plan shows that the government has successfully established explicit and measurable indicators supported by the availability of adequate data.

High total scores reflect the quality of indicators that are explicitly quantitative and/or specific location as the desired outcome(s) at the end of planning. It's just that implementation towards desired outcomes(s) requires human capital, financial capital, and adequate social capital.

In order to have an effective execution, the development plan needs to be accompanied by a new approach that takes into account the linkages of sustainable development challenges. Islamic teachings give the opportunity for shifting the paradigm as a key achievement to reach SDGs. The previous thoughts of the researcher in articles entitled $A \mathrm{New}$ Approach for Sustainable Development Goals in Islamic Perspective [20] and The Shape of Islamic Sustainable Development [21] are summarized into the importance of spiritual injection for all actors of development. Verily, a human is a caliph (leader) in charge of prospering and nurturing the earth and is forbidden to do any damage. While strengthening the financial capital and social capital can be held under Islamic economic systems that guarantees economic, social, and environment integration.

\section{ACKNOWLEDGMENT}

We wish to thank the Directorate of Higher Education Ministry of Research and Technology Indonesia for financially supporting this study through the International Research Collaboration and Scientific Publication Grant, 2018.

\section{REFERENCES}

[1] Čiegis, R., Gineitiene, D. (2008). Participatory aspects of strategic sustainable development planning in local communities: Experience of Lithuania. Ukio Technologinis ir Ekonominis Vystymas, 14(2): 107-117. http://dx.doi.org/10.3846/1392-8619.2008.14.107-117

[2] UNDP. Human Development Report 2016, Human Development for Everyone. http://hdr.undp.org/sites/default/files/2016_human_deve lopment_report.pdf, accessed on May 10, 2018.

[3] The World Bank. World Bank Country and Lending Groups.

https://datahelpdesk.worldbank.org/knowledgebase/artic les/ 906519- world- bank-country- and- lending- groups, accessed on May 10, 2018.

[4] United Nations. Resolution adopted by the General Assembly on 6 July 2017: 71/313. Work of the Statistical Commission pertaining to the 2030 Agenda for Sustainable Development. http://ggim.un.org/documents/A_RES_71_313.pdf, accessed May 10, 2018.

[5] SDG Guide. Chapter 1: Getting to know the Sustainable Development Goals. https://sdg.guide/chapter-1-gettingto-know-the-sustainable-development-goalse05b9d17801, accessed Apr. 8, 2018.

[6] Noorbakhsh, F., Sanjeev, R. (1999). A model for sustainable development: Integrating environmental impact assessment and project planning. Impact Assessment and Project Appraisal, 17(4): 283-293. http://doi.org/10.3152/147154699781767684

[7] Roberts, P., Roger, C.K.C. (1997). A tale of two regions: strategic planning for sustainable development in east and west. International Planning Studies, 2(1): 45-62. https://doi.org/10.1080/13563479708721668

[8] Moles, R., Foley, W., Morrissey, J., O’Regan, B. (2008). Practical appraisal of sustainable developmentmethodologies for sustainability measurement at settlement level. Environmental Impact Assessment Review, 28(2-3): 144-165. https://doi.org/10.1016/j.eiar.2007.06.003

[9] Williams, A. (2013). Experience talks: The views of planners regarding the ability of the new south wales planning system to implement ecologically sustainable development (ESD). Australian Planner, 50(4): 293-303. https://doi.org/10.1080/07293682.2012.749926

[10] Nolon, J.R., Patricia, E.S. (2011). Integrating sustainable development planning and climate change management: A challenge to planners and land use attorneys. Planning \& Environmental Law: Issues and Decisions That Impact the Built and Natural Environments, 63(3): 3-10. https://doi.org/10.1080/15480755.2011.560769

[11] Chimhowu, A.O., Hulme, D., Munro, L.T. (2019). The 'New' national development planning and global development goals: Processes and partnerships. World Development, 120 : 76-89. https://doi.org/10.1016/j.worlddev.2019.03.013

[12] Sasho, K., Eftimov, L. (2015). 'Sustainable Development Planning - The Case Of Macedonia, Meste, 185. https://doi.org/ 10.12709/mest.03.03.01.20

[13] Roughley, A. (1999). Ecologically sustainable local area planning: a framework to enhance integration of community workers and environmental planners. Urban Policy and Research, 17(4): 267-286. https://doi.org/10.1080/08111149908727813

[14] AlQahtany, A., Yacine, R., Haijiang, L. (2013). A proposed model for sustainable urban planning development for environmentally friendly communities. Architectural Engineering and Design Management, 9(3) 176-194. 
https://doi.org/10.1080/17452007.2012.738042

[15] Law of The Republic of Indonesia Number 17 of 2007 On Long-Term National Development Plan of 20052025. Copied by the State Ministry of National Development Planning/National Development Planning Agency (BAPPENAS). Available at https://www.bappenas.go.id/files/6715/3173/4665/RPJP N_2005-2025.pdf, accessed on Jan. 3, 2018.

[16] Conroy, M.M., Berke, P.R. (2004). What makes a good sustainable development plan? Ananalysis of factors that influence principles of sustainable development. Environment and Planning A 2004, 36(8): 1381-1396. https://doi.org/10.1068/a367

[17] Voluntary National Review (VNR) Republic of Indonesia. Eradicating Poverty and Promoting Prosperity in A Changing World. https://sustainabledevelopment.un.org/content/documen ts/15705Indonesia.pdf, accessed on Jun. 1, 2018.

[18] Report of the Inter-Agency and Expert Group on Sustainable Development Goal Indicators
(E/CN.3/2016/2/Rev.1).

https://unstats.un.org/sdgs/indicators/indicators-list/, accessed on Nov. 1, 2018.

[19] United Nation. The Sustainable Development Goals Report.

https://unstats.un.org/sdgs/files/report/2018/TheSustaina bleDevelopmentGoalsReport2018.pdf, accessed on Jun. 5, 2018.

[20] Dariah, A.R. (2016). The shape of islamic sustainable development. In Book Islamic Perspectives on Sustainable Development. Universiti Sain Malasyia \& Islamic Relief Academy 2016, Birmingham, United Kingdom.

https://isdevnews07.blogspot.com/p/publication.html, accessed on Feb. 12, 2018.

[21] Dariah, A.R., SyukriSalleh, M., Shafia, H.M. (2016). A new approach for sustainable development goals in islamic perspective. Procedia-Social and Behavioral Sciences, 219: https://doi.org/10.1016/j.sbspro.2016.05.001 